connections, the thalamic connections, the cortico-pontine connections and the ponto-cerebellar connections.

The important point which, alone, can justify my dwelling so much on these complex and, in part, conjectural anatomical descriptions is to show in how many different ways the labyrinthine impulses can reach and affect the oculo-motor controls and how intimately they are linked up with other muscular controls of head, neck, trunk and limbs. It is unnecessary, for my immediate purpose, to discuss the further controls in which a gnostic or more fully epicritic element is involved.

\title{
A MORPHOLOGICAL STUDY OF THE LATERAL GENICULATE BODY
}

\author{
BY \\ W. E. Le Gros Clark, D.Sc., F.R.C.S. \\ (DEPARTMENT OF ANATOMY, ST. THOMAS'S HOSPITAL, LONDON)
}

IF, in the brain of a simple type of mammal, the optic tract is followed on its course from the chiasma to the roof of the midbrain, it will be found to extend up along the side of the thalamus and to come into relation here with an ill-defined eminence called the lateral geniculate body. This eminence is a local swelling on the dorso-lateral aspect of the thalamus and, in fresh specimens, is white in appearance by reason of its covering of optic tract fibres.

The lateral geniculate body in mammals is one of the main terminal centres of the optic tract and is to be regarded fundamentally as a group of cells differentiated from the main mass of the diencephalon in association with its retinal connections. In the lowliest vertebrates all the fibres of the main part of the optic tract are believed to terminate in the midbrain, but, even in these forms, collaterals of these mesencephalic fibres branch off to end in the optic thalamus. Thus it may be said that in all vertebrates the thalamus is concerned to a greater or lesser degree with the direct reception of visual impulses and, indeed, such a conclusion is to be anticipated from a consideration of the diencephalic origin of the retina and optic nerve and tract in the course of embryological development.

The basic structure of the lateral geniculate body in mammals may best be understood from a section taken through this structure along the line of the optic tract in the brain of a simple insectivore, and such a section is illustrated in Fig. 1, which is taken from the brain of Macroscelides, one of the small elephant shrews. 


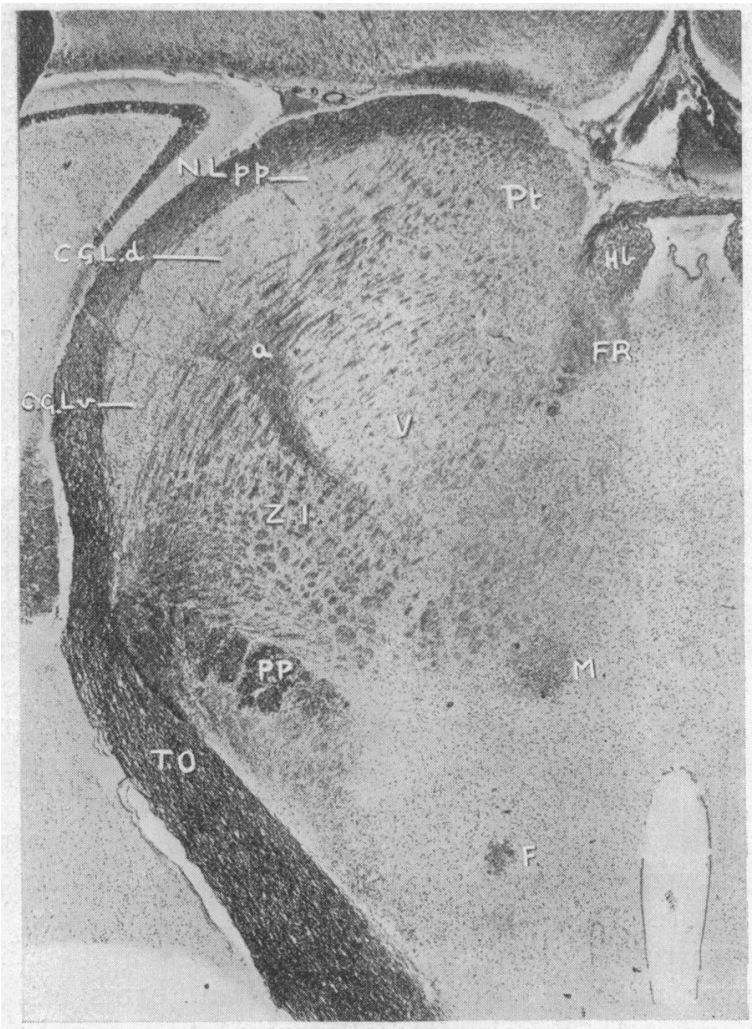

Fig. 1.

Transverse section through the thalamus of the Elephant Shrew (Macroscelides), showing the relations of the lateral geniculate body in a primitive insectivore.

C.G.L.d. Dorsal nucleus of lateral geniculate body. C.G.L.v. Ventral nucleus of lateral geniculate body. a. Fibre tract connecting the dorsal nucleus of the lateral geniculate body with the ventral nucleus of the thalamus. F. Fornix. F.R. Fasciculus retroflexus. Hb. Habenular ganglion. M. Mammillo-thalamic tract. N.L.p.p. Pars posterior of lateral nucleus. Pt. Pretectal nucleus. P.P. Pes pedunculi. T.O. Optic tract.

Here it can be seen that the lateral geniculate body is made up of two distinct nuclei, a dorsal and a ventral.* These nuclear elements are separated by a thin medullary lamina and are characterised. by the different type of their constituent cells as well as by their fibre connections. In general, the ventral nucleus is found to consist of small cells irregularly. scattered among the entering fibres of the optic tract, while the dorsal nucleus contains larger cells which

* Kölliker was the first to divide the mammalian lateral geniculate body into dorsal and ventral nuclei. 
show a tendency to assume a laminated or stratified arrangement that becomes extremely well-marked in the brains of higher mammals. Weigert preparations of normal brains, as well as a study of Marchi degeneration after section of the optic nerve 21,3.4,9., demonstrate clearly enough that retinal fibres make direct connections with both dorsal and ventral nuclei. From Cajal's researches ${ }^{6}$, it is probable that only collaterals of the optic tract fibres terminate in the ventral nucleus, and herein the ventral nucleus of the mammalian lateral geniculate body is comparable with the thalamic optic centre of lowly vertebrates. Cajal also described in detail the manner in which the entering optic fibres. are related to the dorsal nucleus. He showed that in relatively simple types, e.g., rodents, a large proportion of the optic fibres penetrate the dorsal nucleus from the lateral aspect (some, however, also entering from the ventral pole). The general position and relations of the two nuclei of the lateral geniculate body in generalised mammalian brains may be readily understood by reference to the diagrams shown in Fig. 2, which represent these two elements projected on the lateral aspect of the thalamus. The nuclei may most conveniently be considered separately, but it should be noted at this juncture (1) that the ventral nucleus is. evidently the more primitive optic centre, for it shows a progressive diminution in size as it is traced through a comparative anatomical series from more generalised to more highly developed types, and (2) that concurrently with the increase in size and elaboration of other thalamic nuclei in higher mammalian forms (especially the lateral nucleus), the whole lateral geniculate body becomes displaced from a lateral to a ventral position and this displacement is associated with a certain degree of rotation.

The Ventral Nucleus of the Lateral Geniculate Body.-This nucleus lies below and in front of the dorsal nucleus (Fig. 2). It is penetrated by optic fibres from its ventral aspect and many of these fibres pass through it without interruption to reach the dorsal nucleus ${ }^{26,9}$. One fundamental fact that stands out as a result of a comparative anatomical study of the ventral nucleus of the lateral geniculate body in primitive mammalian brains is that the nucleus is nothing more than a differentiated lateral segment of that part of the pars ventralis diencephali which is called the subthalamus. This is indicated in the first place by purely topographical relations and by the fact that the cells are of the same type, for, cytoarchitecturally, the ventral nucleus grades insensibly into the zona incerta of the subthalamus. In such a form as Macroscelides, indeed, the ventral nucleus is only to be distinguished from the rest of the subthalamus by the fact that it receives collaterals from the optic tract and that it is incompletely cut off by bundles of fibres which run from the caudal part of the internal capsule to the tectal 
region of the brain. This broad continuity of the ventral nucleus of the lateral geniculate body with the subthalamus is also very evident in sections of the developing thalamus of higher mammals. In the adult brains of such forms, however, the association of the ventral nucleus with the zona incerta is not so obvious by reason of the lateral displacement of the former which is partly due to the greater development of the lateral and ventral nuclei of the thalamus. The rich collection of medullated fibres which run medially and caudally from the ventral nucleus into the zona incerta (ventral to

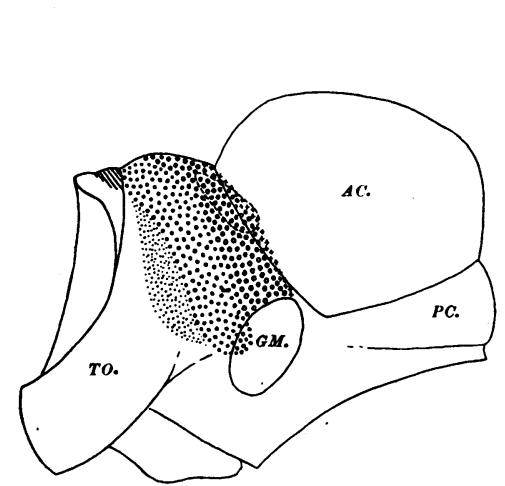

A.

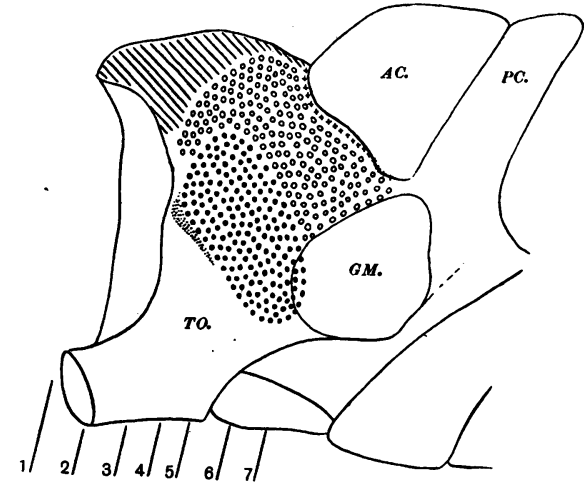

FIG. 2

B.

Lateral view of the thalamus of (A) the Tree-shrew (Tupaia), and (B) (Tarsius). Some of the thalamic nuclei have been projected on to the surface to indicate their relative position and extent. Oblique lines= lateral nucleus, fine dots = ventral nucleus of lateral geniculate body, coarse dots $=$ dorsal nucleus of lateral geniculate body, circles $=$ pars posterior of lateral nucleus (pulvinar), crosses = large-celled nucleus of optic tract.

the ventral medullary lamina of the thalamus) is further evidence of the relation between the two. I have observed this fibre connection in insectivores, and in the primitive Primate, Tarsius. ${ }^{8}$ Gurdjian ${ }^{14}$ has also noted (in the rat) that the ventral nucleus is in intimate synaptic relation with the zona incerta and he believes that it is likewise associated with Meynert's commissure. Connections have also been described ${ }^{28}$ between the ventral geniculate nucleus and the tectal region (superior colliculus and probably also the pretectal nucleus). ${ }^{9}$ On the other hand there is no evidence that the nucleus gives off any cortical fibres, and neither does it receive any corticifugal fibres. ${ }^{2}$

From its position, structure and connections, therefore, the ventral nucleus of the lateral geniculate body may be regarded as essentially a subthalamic optic centre with tectal connections. In spite of the latter, it is primarily a dependency of the subthalamus rather than of the tectum, and this is related to the fact that it 
retains a closer topographical relation with the subthalamus than with the roof of the midbrain in the displacements which occur as the result of differential developments of other parts of the thalamus.

Since the ventral nucleus of the lateral geniculate body is con-nected only with relatively low functional levels of the brain and does not give rise to any part of the optic radiations (being, indeed, completely independent of the cortex), it may be expected that in higher mammalian forms in which the activities of the tectal and subthalamic centres become progressively subordinated to those of the telencephalon, the nucleus will become a much less significant structure. This, in fact, is the case. In the brain of the treeshrew, Tupaia (Fig. 2), in which the superior colliculus reaches an immense size, the ventral nucleus of the lateral geniculate body is correspondingly large. In the most primitive lemuroid brain-that of Microcebus murinus - (which is readily comparable with Tupaia), the midbrain is very much smaller relatively to the cerebral cortex, and the ventral geniculate nucleus, though easily discernible, is much reduced in size. ${ }^{10}$ In higher Primates, the nucleus has been stated to be absent altogether, but it is probably usually to be recognised in the form of small cells which are scattered among the fibres of the optic tract as they enter the main part of the geniculate body, and which are sometimes referred to as the pregeniculate nucleus. ${ }^{28}$ It may be noted that in these higher forms, as a consequence of the relative displacement of the lateral geniculate body, the ventral nucleus comes to be situated rather anteriorly than ventrally to the dorsal nucleus. It is interesting, also, to note that in the human embryo the ventral nucleus of the lateral geniculate body appears to be as distinct as it is in simple mammalian brains (Fig. 5). A further point about the ventral geniculate nucleus in higher mammals is that it receives only crossed fibres of the optic tract, ${ }^{3}$ and this fact again emphasises the primitive character of the ventral as compared with the dorsal nucleus.

The Dorsal Nucleus of the Lateral Geniculate Body.-The dorsal nucleus, in primitive mammalian brains, is made up of the same type of cell as the ventral or main sensory nucleus of the thalamus and is closely applied to the lateral aspect of this nucleus, being separated from it by the lateral medullary lamina which is largely made up of fibres passing between the tectal region and the internal capsule. This topographical relation is also to be found in the thalamus of the human embryo (Fig. 5), and, indeed, comparative anatomical and embryological data indicate that the dorsal geniculate nucleus is to be regarded primarily as the differentiated lateral part of the ventral nuclear mass of the thalamus. This relation is also shown by a consideration of the condition in those insectivores in 
which the optic nerves are very poorly developed and the visual cortex but feebly differentiated (e.g., the common shrew, Sorex), for, in this form, the dorsal nucleus of the lateral geniculate body appears to undergo retrogressive changes and to become merged indistinguishably again with the ventral thalamic nucleus. Further, an analogy based upon functional level is indicated by the fact that the dorsal geniculate nucleus bears the same relation to visual impulses passing through the thalamus to the cortex as does the ventral nucleus of the thalamus to somaesthetic impulses. If the dorsal nucleus of the lateral geniculate body, then, is formed by the splitting off of the lateral part of the ventral thalamic nucleus, it may be expected to retain its connection with this nucleus by fibre connections. In small mammalian brains in which the lateral geniculate body, though completely differentiated, remains still of a simple type, such a connection is easy to see, and abundant medullated fibres can be traced emerging from the medial aspect and passing medially into the ventral thalamic nucleus. In brains like that of Macroscelides (Fig. 1) and.the fruit bat, Pteropus, in which, while the optic tracts are of a large size, the visual cortex is still comparatively poorly differentiated, this intrathalamic connection of the dorsal geniculate nucleus is very striking. In an animal like the Virginian opossum, in which the optic system is not very strongly developed, the connection is only feebly indicated, ${ }^{26}$ and in higher forms where rich geniculo-cortical connections (optic radiations) are developed in association with a progressive elaboration of the visual cortex, these intrathalamic connections also become less evident.

It has been shown that the ventral geniculate nucleus is connected by fibre paths with the superior colliculus. It is probable that such a connection also exists in regard to the dorsal nucleus. This, however, is not easily proved by ordinary degeneration experiments for the reason that the tectal fibres from the ventral nucleus largely pass through or in very close relation with the dorsal nucleus. However, in normal Weigert preparations, fibres may be observed leaving the lateral margin of the dorsal nucleus to join the optic tract as it runs on towards the roof of the midbrain. These fibres are probably destined to reach the superior colliculus and the pretectal nucleus, and perhaps also the pars posterior of the lateral nucleus or pulvinar.*

The dorsal nucleus of the lateral geniculate body is interconnected by short fibres with the neighbouring part of the pars posterior of the lateral nucleus. This fibre connection is readily to be seen in simple types of brain in which the lateral geniculate body preserves its simple form and is not encapsuled by a dense feltwork of

\footnotetext{
* For a discussion of the homologies of the pulvinar and the fars posterior of the lateral nucleus, $\operatorname{see}^{8}$.
} 
medullary fibres. 'The most significant fibre connections of the dorsal nucleus in higher mammals are those which run between it and the occipital cortex in both directions. These corticipetal fibres form the optic radiations. They are composed of the axons of the cells of the dorsal nucleus which emerge from the medial surface of the nucleus (or from the dorsal surface in the brains of more advanced types in which a rotation of the lateral geniculate body has occurred) and, coursing through the posterior part of the internal capsule, terminate in the area striata or visuo-sensory cortex.

The Évolution of the Lateral Geniculate Body in the Lower Vertebrates.- Having considered the main features of the lateral geniculate body in generalised mammalian brains, it is convenient to trace its evolutionary origin from that of submammalian forms. The general opinion obtains that the tectum of the midbrain is the primitive termination of the optic tract and that, with the gradual process of prosencephalisation, the main visual centres shift forwards gradually to the forebrain. This is in general true, but the fact remains that the retina develops as an appendage of the thalamic part of the brain tube in the embryo and, as we pointed out above, it is therefore to be expected that the diencephalon would be associated from the first with the reception, in part at least, of visual impulses. Actually in all vertebrates studied to this end optic fibres can be traced into the diencephalon, though the majority do terminate in the midbrain in the most primitive forms. Even in the lamprey, a cyclostome, in which the midbrain had been regarded as the sole terminal station for the visual impulses, collaterals of optic tract fibres have been demonstrated to end in a group of cells in the lateral wall of the diencephalon..$^{25}$

As far as amphibia are concerned, in the frog, ${ }^{13,27}$ the optic tract after decussation and sending off a basal bundle (vide infra) passes -up the side of the thalamus to reach a superficial collection of cells which has been called the lateral geniculate body, and further dorsally it sends collaterals to another nucleus which Wlassak and Bellonci named the nucleus antero-superior of the lateral geniculate body. Herrick ${ }^{15}$ failed to find in Necturus a differentiated nucleus corresponding to Wlassak's lateral geniculate body (perhaps because in this urodele the optic system is poorly developed), but he found a fairly well-differentiated thalamic centre apparently homologous with the nucleus antero-superior of Bellonci ${ }^{1}$ and Wlassak. ${ }^{27}$ This centre Herrick calls the pars optica thalami, and it is to be regarded as essentially a differentiated part of his pars dorsalis thalami. Since the latter element in the amphibian brain is the great somatic sensory receptive centre of the diencephalon, its homologue in the mammalian thalamus is undoubtedly to be found in the ventral group of nuclei. It seems probable, therefore, that the pars optica thalami of Herrick is the primordium of the dorsal nucleus of the 
lateral geniculate body of mammals (which, as pointed out above, is formed as a differentiation of the ventral thalamic nucleus). If this is so, the "lateral geniculate body" described in some amphibia probably represents the ventral nucleus of the mammalian lateral geniculate body. This interpretation brings the amphibian optic centres into line with those of the reptilia.

A lateral geniculate body in the reptilian brain has been described by many investigators $1,5,11,12,16,18,20$. It forms (in transverse sections

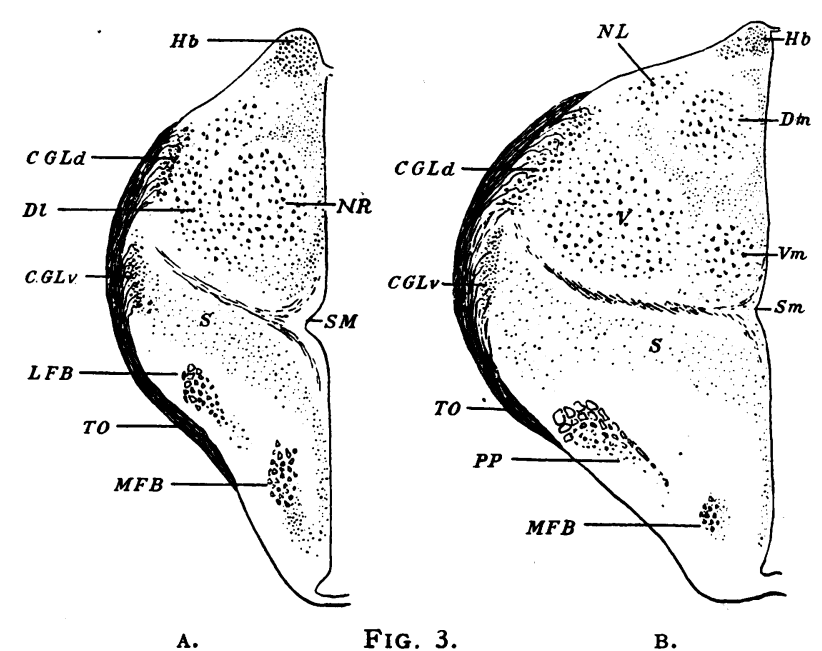

Schematic representations of transverse sections through the thalamus of (A) Reptilian brain, and (B) Mammalian brain, showing the homologies of certain diencephalic elements.

C.G.L.d. Dorsal nucleus of lateral geniculate body. C.G.L.v. Ventral nucleus of lateral geniculate body. Dl. Nucleus dorso-lateralis anterior. Dm. Dorso-medial nucleus. Hb. Habenular ganglion. L.F.B. Lateral forebrain bundle. M.F.B. Medial forebrain bundle. N.L. Nucleus lateralis. N.R. Nucleus rotundus. P.P. Pes pedunculi. S. Subthalamus. S.M. Sulcus medius. T.O. Optic tract. V. Ventral nucleus. Vm. Nucleus medio-ventralis.

of the thalamus) a vertical band of cells lying on the lateral surface of the diencephalon and is reached by the optic tract which splits into two branches to enclose it on its lateral and medial aspects. It is to be noted that, before it has reached the geniculate body, the optic tract has already given off a basal root to the basal optic ganglion (nucleus ectomammillare) and, according to some observers such as Bellonci, fibres to the subthalamic region (representing the axillary bundle described in amphibia by Wlassak and Herrick). These two roots are apparently equivalent to the anterior and posterior accessory optic tracts of mammals $\left(\mathrm{see}^{9,26}\right)$. The next nucleus to be reached by the optic tract as it courses dorsally in 
mammals is the ventral necleus of the lateral geniculate body. From its position in the course of the optic fibres, therefore, the lateral geniculate body of reptiles appears to be the homologue of the mammalian ventral geniculate nucleus. This identification is confirmed by other considerations. The reptilian lateral geniculate body receives mainly, if not entirely, collaterals of the optic tract fibres, as does the ventral geniculate nucleus of mammals. Topographically, the body is related medially to a collection of cells which has been called the "area triangularis" 16,11 and, in fact, the cells of this area merge with those of the geniculate body without any clear limits. Now, by its general relations, its position in regard to the sulcus medius of the third ventricle, and by its continuity with the area ventralis anterior of Huber and Crossby, and Durward (which is itself continuous behind with the entopeduncular nucleus and in front comes into synaptic relations with fibres of the stria terminalis), it is evident that this area triangularis is a part of the pars ventralis diencephali (subthalamus). This is also indicated by the fact that the area contains olfactory projection tracts and is separated from the nucleus dorso-lateralis anterior (a somatic nucleus) by the diencephalo-periventricular system of fibres which seems in part to occupy the position of the ventral medullary lamina of the mammalian thalamus. Moreover, the area triangularis seems to be the equivalent of the diffuse "ventral thalamic nuclei" of the reptilian thalamus which were described by de Lange ( $c f$. figures in the papers of de Lange, ${ }^{20}$ Huber and Crossby, ${ }^{16}$ and Durward ${ }^{11}$ ) and a part of which this author identifies as the homologue of Field $\mathrm{H}$ of Forel (of the mammalian subthalamus). It therefore appears that the lateral geniculate body in reptiles, as it has been generally described, bears the same topographical relation to the reptilian equivalent of the subthalamus that the ventral nucleus of the lateral geniculate body does to the subthalamus in mammals. A consideration of the fibre connections leads to the same interpretation. Three main fibre connections have been described for the reptilian lateral geniculate body-a fasciculus geniculatus descendens, a tractus geniculo-pretectalis, and a tractus geniculo-tectalis. The first has been described by Beccari and Huber and Crossby, and was traced by them into the posterior part of the subthalamic region. A tract described in the chamaeleon by Shanklin, ${ }^{24}$ and called by him the tractus geniculo-hypothalamicus, is clearly the same connection. In this reptile, in which the optic mechanism is unusually well-developed, it could be traced as a broad band of fibres spreading over most of the area between the nucleus rotundus dorsally and the ventral peduncle of the lateral forebrain bundle ventrally, many of the fibres terminating in hypothalamic nuclei.

This subthalamic connection of the reptilian lateral geniculate 
body, as well as its connections with the tectum, clearly corresponds very well with the fibre connections of the ventral nucleus of the lateral geniculate body of mammals, and finally establishes the homology of these structures. The geniculo-pretectal tract of reptiles probably represents the tract of the same name in mammals though, in the latter, it has not been certainly demonstrated (except on the basis of such an analogy) whether the ventral or the dorsal nucleus gives origin to this connection. The question now arises as to whether there is any equivalent of the dorsal geniculate nucleus of mammals in the reptilian thalamus. It has been suggested by some authorities that this is not to be expected seeing that the dorsal nucleus is essentially the nucleus of origin of the cortical optic radiations, and no visual cortex has been demonstrated to exist in the reptilian cerebrum. But the dorsal geniculate nucleus has intrathalamic connections with the ventral thalamic nucleus which are especially rich in certain primitive mammals and which presumably anticipated in evolutionary development, the cortical connections. It has already been shown that the dorsal nucleus in mammals is differentiated out of the ventral nucleus of the thalamus-the main somatic sensory nucleus of the diencephalon. Huber and Crossby state that in the crocodile the optic tract, after passing by the lateral geniculate body, comes into relation with the nucleus dorso-lateralis anterior in the lateral part of which some optic fibres actually terminate. Now there is little doubt that the nucleus dorso-lateralis anterior of reptiles is to be regarded as homologous with a part of the ventral thalamic nuclear group of the mammalian thalamus and, this being so, the relation of its superficial cells to terminal optic fibres almost certainly indicates that they represent the undifferentiated anlage of the dorsal geniculate nucleus. Moreover, in some reptiles at least (e.g., Sphenodon), these superficial cells become differentiated to form a fairly circumscribed nucleus which has been termed the dorsal nucleus of the lateral geniculate body by some authors. ${ }^{11,5}$ The relative position of this nucleus in regard to the optic tract and to other thalamic elements provides considerable justification for this nomenclature. There is in Sphenodon also a ventral nucleus of the lateral geniculate body which, as Cairney indicates, corresponds with the area commonly termed the lateral geniculate body in other reptiles, and it is this element which gives off the fasciculus geniculatus descendens.

The homologies of the lateral geniculate body in reptilians and mammals are illustrated diagrammatically in Fig. 3.

The Evolution of the Lateral Geniculate Body in Mammals.-An account has been given of the structure and connections of the lateral geniculate body in a primitive and generalised mammalian brain. As may be readily apprehended from the reconstructions 
figured (Fig. 2), the lateral geniculate body in such a form stretches obliquely downwards and backwards along the whole extent of the lateral aspect of the thalamus from its anterior to its posterior limits. The relatively large size of the body in primitive insectivores (in relation to the size of the thalamus as a whole) and its extension forwards should be noted, for some observers have expressed surprise that the lateral geniculate body in reptiles reaches to the anterior part of the thalamus. The primitive position of the body becomes considerably altered in higher mammals, principally as the result of the development of adjacent thalamic nuclei. Thus its caudal part becomes first displaced more ventrally (in association with an enlargement of the pulvinar or pars posterior of the lateral nucleus), and subsequently, as a direct result of the increasing elaboration of the main lateral thalamic nucleus, the whole lateral geniculate body is pushed down so that it comes to lie on the ventro-lateral aspect of the thalamus. Further, as we shall see below, this displacement is also associated with a rotation and, in the higher Primates, with a bending of the lateral geniculate body on itself.

It has been pointed out by several observers ${ }^{28,17}$ that the dorsal and ventral nuclei show an inverse ratio in their development in higher mammals, and this is precisely what is to be anticipated from a consideration of their early phylogenetic history and their connections. The ventral geniculate nucleus is the more primitive element and, as a dependency of the subthalamus with tectal connections, it becomes progressively superseded by the dominance of the dorsal nucleus with its cortical connections. But even in the simplest mammalian brains the dorsal nucleus is distinctly larger than the ventral nucleus. The fate of the ventral nucleus has been dealt with above. The most important diencephalic centre of vision in reptiles is destined to be reduced in higher mammals to an insignificant collection of scattered cells which lie among the fibres of the optic tract entering the elaborate dorsal nucleus, which, in the larger Primates, constitutes what is now called the pregeniculate nucleus or the corpus pregeniculatum.

The fate of the dorsal nucleus of the lateral geniculate body in the higher mammalian series is a history of progressive elaboration which proceeds pari pass $u$ with the development of the visual cortex of the cerebrum. Disregarding the divergent mammalian groups such as the ungulates and carnivora, the changes which occur in the transition from the simple form of the dorsal nucleus of the lateral geniculate body of primitive mammals to the complicated structure found in higher Primates may best be illustrated by the consideration of a series of animals which-as indicated by detailed comparative anatomical studies-most closely approximate to a true phylogenetic series in the evolution of the higher Primates. In a generalised insectivore such as the hedgehog the dorsal nucleus 
appears in transverse section as a lens-shaped group of cells closely applied to the subjacent ventral thalamic nucleus, and lying rather on the dorso-lateral aspect of the thalamus. There is here no differentiation in the internal structure of the dorsal nucleus.

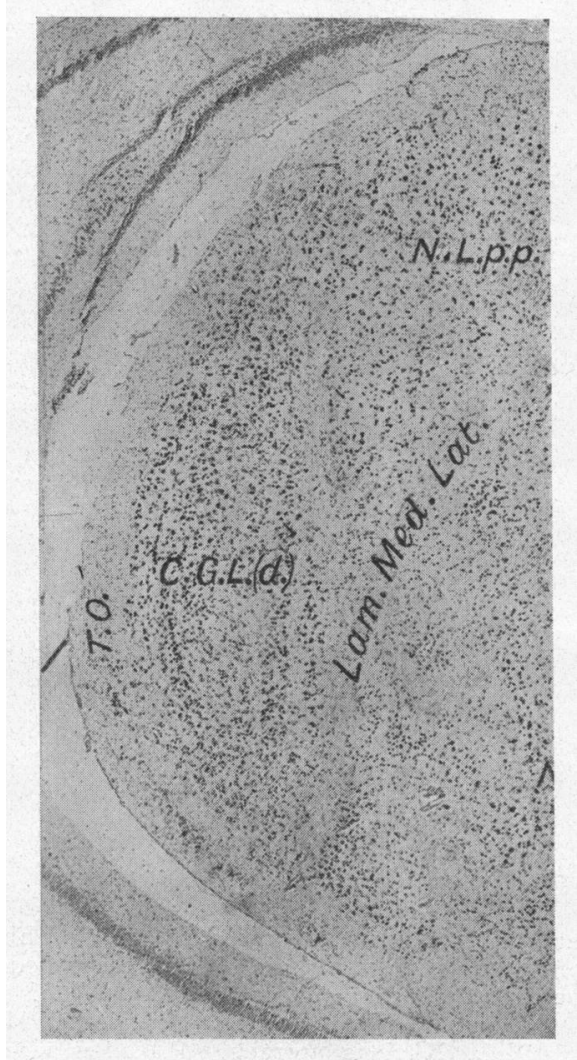

Fig. 4.

Transverse section of the lateral geniculate body of the Tree-shrew (Tupaia minor).

C.G.L.d. Dorsal nucleus of lateral geniculate body. N.L.p.p. Pars posterior of lateral nucleus. T.O. Optic tract.

Optic tract fibres enter from the lateral aspect and to some extent at the ventral border. In Tupaia minor (the lesser tree-shrew), an insectivore with a number of singularly primate-like characters, the dorsal nucleus is much larger and, moreover, its cells show a definite tendency to a laminated arrangement. The cells of the lateral and medial laminae are conspicuously larger than those in the centre of the nucleus. The increase in size and the incipient 
differentiation in internal structure of the dorsal nucleus of the lateral geniculate body in Tupaia is associated with the high grade of development of other elements of the visual apparatus of the brain, e.g., the large optic nerves, the relative size of the pulvinar, and the extent and differentiation of the visual cortex. It is interesting to note that in the thalamus of the early human embryo the dorsal nucleus of the lateral geniculate body shows a relative

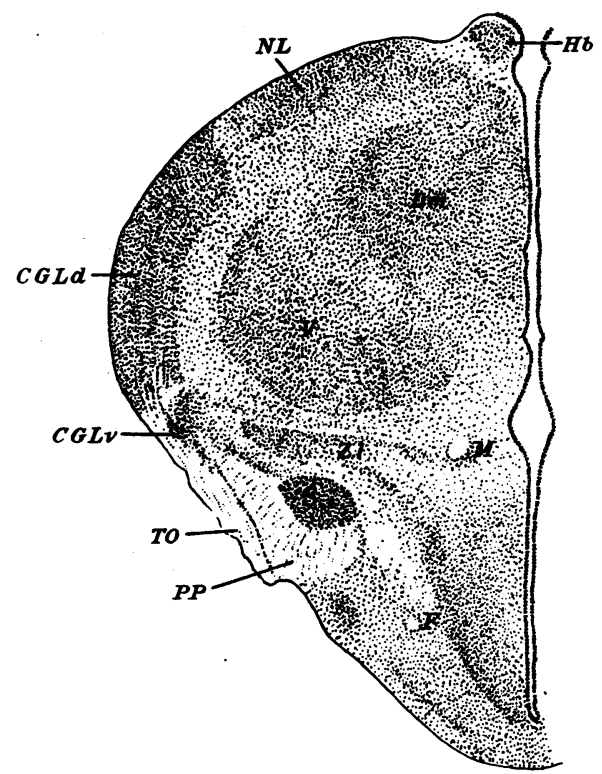

Fig. 5.

Transverse section through the thalamus of a $92 \mathrm{~mm}$. human embryo. C.G.L.d. Dorsal nucleus of the lateral geniculate body. C.G.L.v, Ventral nucleus of the lateral geniculate body. Dm. Dorso-medial nucleus. F. Fornix. Hb. Habenular ganglion. M. Mammillothalamic tract. N.L. Nucleus lateralis. P.P. Pes pedunculi. T.O. Optic tract.

size and topographical position which approximates very closely to the condition in an insectivore such as the tree-shrew. The change in the dorsal nucleus of Tupaia as compared with that of other insectivores foreshadows the much more striking changes to be found in the Primates. In some of the most primitive forms of this group there seems to be little advance on the condition found in the tree-shrew. In Cheirogaleus, for instance, the dorsal nucleus of the lateral geniculate body has the same position and shape, the only important difference being a more pronounced lamination of its constituent cells. ${ }^{19}$ As in Tupaia, the fibres of the optic tract enter the nucleus largely from its lateral aspect, and 
the optic radiations emerge from its medial concave surface. In Fig. 6 is shown the appearance of a section of the lateral geniculate body in the mouse-lemur (Microcebus murinus), one of the most primitive living members of the Primates. Here the lamination and differentiation of the dorsal nucleus is more obtrusive. It will be noted that the lateral laminae consist of much larger cells than those of the medially situated laminae. The appearance of superficial large-celled laminae (one or two) is a characteristic feature of the lateral geniculate body of Primates, and so far as is known it is conspicuously present in every Primate with the curious exception of Tarsius. ${ }^{8}$ The further changes which occur in the dorsal nucleus in higher Primates (besides the displacement of the nucleus as a whole) are a result of the folding of these laminae and their cytoarchitectural differentiation.

In all monkeys (even in relatively simple types such as the marmoset) the laminae have become completely everted. This change is best understood by reference to Fig. 6 . As a result of this eversion, a definite hilum is formed, directed ventro-medially, and it is from this direction that optic tract fibres (as well as branches of the posterior cerebral artery) enter the nucleus. At the same time the medial laminae are curved so as to form a dorsal convexity from which the optic radiations emerge. This process of eversion is evidently associated with and provides for an expansion of the more medially situated cell laminae and it is interesting to note that it is these medial laminae which are related to the binocular type of vision which attains such a high degree of development among the Primates. ${ }^{4}$ The intermediate steps which culminate in the formation of the completely everted type of lateral geniculate body may be traced in different members of the group of Primates as well as by embryological studies. In man, as in the African anthropoid apes, the eversion is not so complete. A lateral "spur" is left, or, in other words, the original dorsal and ventral margins of the dorsal nucleus of the lateral geniculate body have not become approximated to complete the formation of the hilum. In the orang utan, the dorsal nucleus seems to be remarkably simple (according to Kornyey's description and figure ${ }^{19}$ ), and the laminae in this ape are but little curved. It is not a little remarkable that, as regards these changes in the lateral geniculate body, the pithecoidea should have advanced further than man and the anthropoid apes (with the significant exception of the gibbon which, in this respect, resembles the monkeys).

A detailed study of the manner in which the laminae of the lateral geniculate body become convoluted in difterent mammalian groups would no doubt provide interesting and valuable data for the assessment of systematic affinities. This taxonomic aspect of the problem is well illustrated within the limits of the order of Primates 

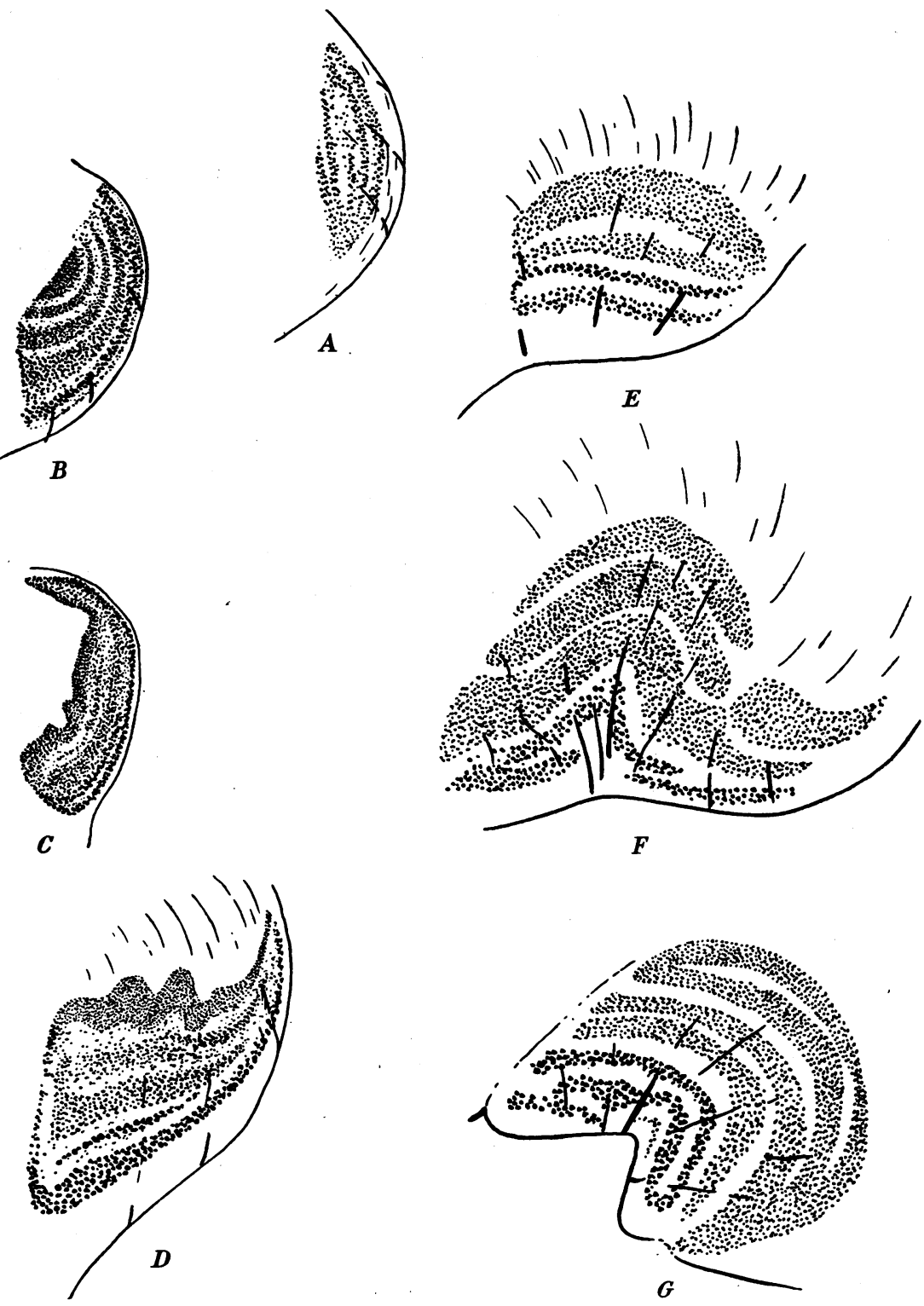

Fig. 6.

The appearance in transverse section of the dorsal nucleus of the lateral geniculate body of (A) Tree-shrew (Tupaia), (B) Mouse Lemur (Microcebus murinus), (C) Coquerell's Dwarf Lemur (Microcebus Coquerelli), (D) Lemur catta, (E) Orang utan (after Kornyey), (F) Man, (G) Cercopithecus, showing the arrangement of the cell laminae and the direction of the entering blood vessels. The lateral side of the geniculate body is towards the right. 
as is indicated in the diagrams in Fig. 6. It will be recalled that systematists generally recognise three suborders of the Primates, Lemuroidea, Tarsioidea, and Anthropoidea. The first includes the true lemurs of Madagascar, the lorises and pottos, the latter includes monkeys, apes, and man, while the suborder Tarsioidea is represented to-day by only one genus, Tarsius. As regards the first two suborders there have been for many years sporadic discussions, often of an animated and even acrimonious nature, as to the precise nature of the affinities of the Anthropoidea with the Lemuroidea.

A survey of a graded series of members of the Lemuroidea (e.g., the series Microcebus murinus, Microcebus Coquerelli, Lemur Macaco) indicates that in this suborder the laminae of the lateral geniculate body have become progressively folded in a direction quite the opposite of the condition in the Anthropoidea. In the mouselemur the lamination is particularly distinct, and the laminae show a curvature which is in conformity with the convex lateral surface of the thalamus. In Coquerell's dwarf lemur' a tendency is shown towards an incurving of the laminae so that the medial concavity of the geniculate body (from which the optic radiations emerge) is more exaggerated. The medially situated laminae appear to be "buckled up" as the result of this inversion so that it is thrown into a few irregular folds. In Lemur this inversion of the laminae is also to be seen, and the medial laminae are more distinctly folded into a series of small undulating convolutions. Also, the whole nucleus has been rotated to some degree so that the lateral surface now is directed ventro-laterally.

Thus, while in the Anthropoidea an everted type of lateral geniculate body is developed, with the production of a medioventral concavity or hilum at which fibres of the optic tract and branches of the posterior cerebral artery enter the nucleus and a dorso-lateral convexity from which the optic radiations emerge, in the Lemuroidea there has been evidently a progressive inversion so that the optic tract fibres and blood-vessels enter from a ventrolateral convex surface and the optic radiations emerge from an accentuated dorso-medial concavity. In both groups there has clearly been an expansion of the medial laminae which, as we may infer from the experimental reseaches of Brouwer and his colleagues, are predominantly related to the binocular type of vision. In the Anthropoidea this expansion has been met by the eversion of the medial laminae while in the larger members of the Lemuroidea it has been accommodated by the crinkling up of these laminae into a series of small convolutions. We may infer, from a consideration of these opposite tendencies in the elaboration of the lateral geniculate body in these two suborders, that in the common ancestral form from which they have presumably been derived, the laminae 
of the lateral geniculate body must have been of simple disposition and uncomplicated by a folding in either direction. Taking all the available data into account, there is reason to presume that the lateral geniculate body of this hypothetical ancestor would hardly have been much more elaborate than it is in the larger tree-shrews. In other words, the Anthropoidea and Lemuroidea must have diverged in the process of their evolution from a very primitive ancestral type.

The significance of the Lamination of the Dorsal Nucleus of the Lateral Geniculate Body. - In the elaborate types of lateral geniculate body, lamination of its constituent cells is a very conspicuous feature. In the higher Primates, e.g., man and most monkeys, a six - layered structure is produced, consisting of two large-celled superficial laminae and four deeper layers of medium-sized cells. These layers of the fully developed lateral geniculate body may conveniently be designated by the figures $1 a, 1 b, 2 a, 2 b, 3 a$ and $3 b$. There is some reason to believe that this six-layered type is derived from a three-layered type. Thus in sub-primate forms such as carnivora ${ }^{23}$ there is a superficial large-celled lamina and two deeper laminae of medium cells, and in the primitive Primate Tarsius the trilaminar type is also to be found. ${ }^{8}$ The significance of this primary lamination is obscure, but it has been suggested that the lamination in higher Primates is related to the hemi-decussation of the optic tract. Minkowski ${ }^{22}$ has described and figured the changes in the lateral geniculate body of a monkey which occur after enucleation of one eye. He found chromatolytic degeneration in one set of alternate laminae of the lateral geniculate body of one side, and in the other set of alternate laminae of the opposite side. From this he inferred that crossed and uncrossed fibres terminate alternately in successive cell laminae. This conclusion has not been generally accepted. Brouwer, in his enquiry into the question of localisation in the lateral geniculate body, depended on the Marchi method. He found that in the monkey the "monocular" area is limited to the basal part (roughly corresponding, by the way, to the superficial large-celled lamina which I have here called lamina $1 a$ ). As regards the retinal fibres related to the binocular field of vision, he could only go so far as to conclude that the crossed and uncrossed fibres are closely intermixed in the lateral geniculate body and he was unable therefore to confirm or disprove Minkowski's conclusion.

I have recently been fortunate enough to obtain material bearing on this most important question. The first specimen is the brain of a monkey (Macacus nemestrinus) whose left eye had been destroyed as the result of an accident seven months before death. For this specimen I am indebted to Dr. Zuckerman and the Zoological Society of London. An examination showed that the 

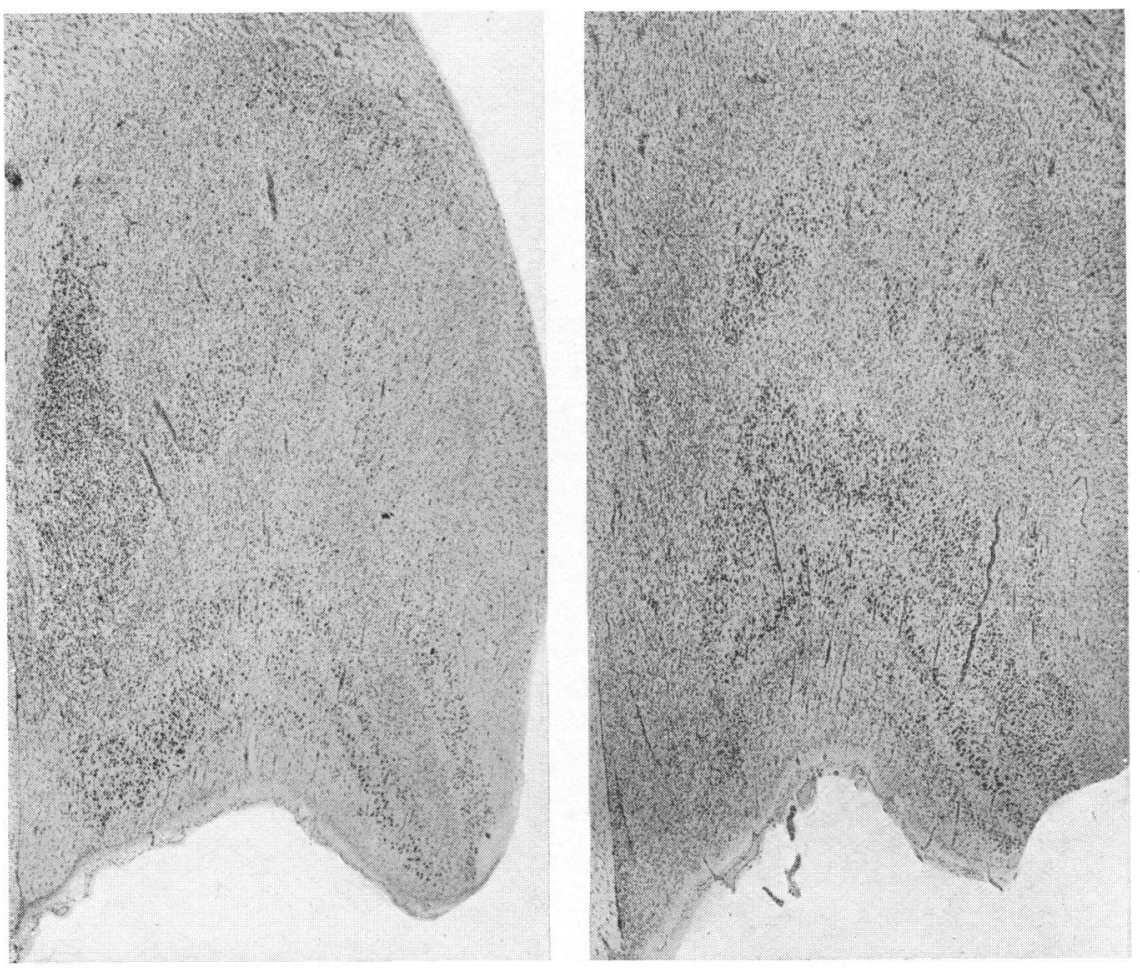

A.
PLATE 1.
B.

Sections through the left (A) and the right (B) lateral geniculate bodies of Macacus nemestrinus in which the left eye had been destroyed 7 months before death. In both cases the lateral aspect is towards the right. 


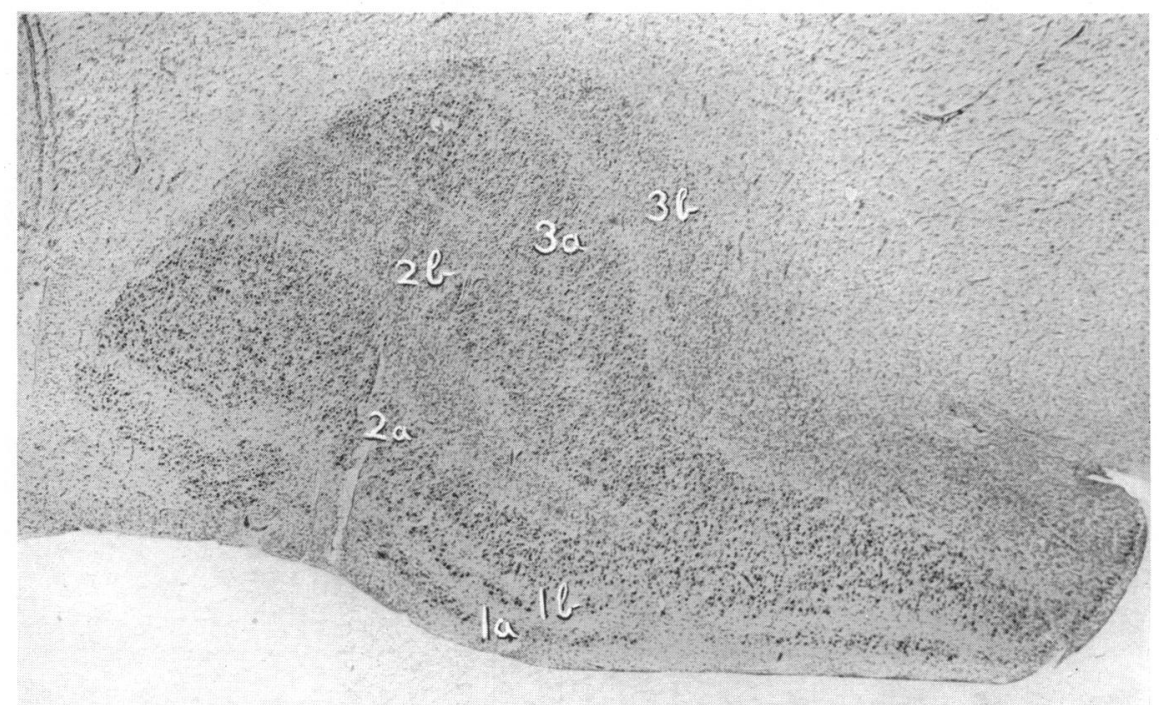

\section{Plate 2B.}

Sections through the left (A) and the right (B) lateral geniculate bodies of a woman whose left eye had been removed for glaucoma 2 years before death. In both cases the lateral aspect is towards the right. 
left eye had undergone complete atrophy and the corresponding nerve had also degenerated. The geniculate bodies were cut transversely and numerous sections through the central part of the body stained with Borell's methylene blue. Photographs of typical sections are shown in Plate 1 . The cells of lamina $1 a$ on the right side had undergone complete chromatolysis with the exception of a few scattered cells seen in some sections which were pale and atrophic. On the left side this layer appears normal. Lamina $1 b$ on the right side consists of a regular layer of large and deeply

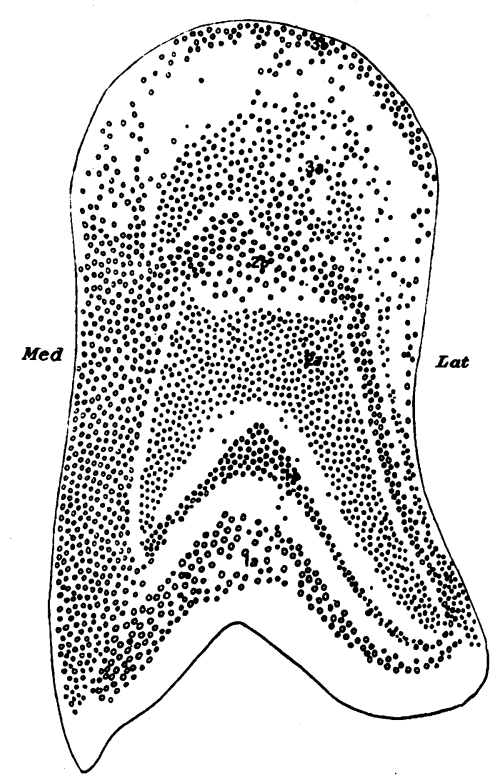

FIG. 7.

Diagram of a transverse section of the lateral geniculate body of Macacus nemestrinus, constructed from a study of serial sections through the middle of the body. The cell laminae receiving crossed fibres of the optic tract are represented by circles, those receiving uncrossed fibres by black dots.

staining cells of normal appearance, while on the left side they are shrunken and atrophic except for a few odd cells here and there. - Lamina $2 a$ on the right side is a thick lamina of closely packed normal medium-sized cells, and on the left this layer is completely atrophied. Lamina $2 b$ contains no normal cells at all on the right side, and on the left it contains numerous cells of normal appearance, somewhat diffusely arranged. Lamina $3 a$ on the right side appears normal and on the left has disappeared except for a few isolated cells seen here and there in odd sections. Lamina $3 b$ has undergone complete atrophy on the right, and on the left side it is still to be distinguished. In Fig. 7 a composite diagram is shown in 
which the distribution of normal cells of the right and left lateral geniculate bodies has been plotted out from the study of serial sections through the middle of the body. It is clear that there is a very definite relation between the lamination and the termination of crossed and uncrossed fibres of the optic tract, even though a very slight intermingling may occur in laminae $1 b$ and $3 a$. Crossed fibres end in laminae $1 a, 2 b$ and $3 b$, and uncrossed fibres in laminae $1 b, 2 a$ and $3 a$. It will be observed that in the central part of the lateral geniculate body laminae $2 b$ and $3 b$ fuse to form a thick column of cells on the medial side, and thus it seems that a relatively greater proportion of crossed fibres terminate in the more medial than in the more lateral parts of the body. Further, if the body is considered as a whole, it is seen that the more peripherally situated laminae receive only crossed fibres.

The second case which I wish to report here is that of a woman, aged fifty-four years, who had had her left eye removed for glaucoma two years before death. At the autopsy nothing abnormal was found on macroscopical examination of the brain except for atrophy of the left optic nerve. The lateral geniculate bodies were excised and paraffin sections were made in a coronal plane, the sections being stained with Borell's methylene blue. The normal human lateral geniculate body is very conspicuously laminated and, as in monkeys, six laminae can be recognised of which the two superficial are formed of large deeply staining pyriform cells from the deep aspect of which long branching processes arise, while the four deeper laminae are composed of medium-sized cells, triangular and fusiform in shape and fairly closely packed together. In this particular case cellular atrophy of the laminae was found as in the monkey. Microphotographs of the geniculate bodies of the two sides are shown in Plate 2. On the left side, lamina $1 a$ is a relatively thick layer of large deeply staining cells of the normal type, the layer being interrupted only here and there by the passage of blood vessels. The fine branching dendritic processes of these cells show up well with the stain used and form a rich matrix of intertwining processes which permeate the whole layer. On the right side there are no cells of normal size left. They have all shrunken to the size of the cells in the deeper layers or smaller, and a high-power examination shows that they have undergone chromatolytic changes and the dendrites are very much less conspicuous. On the other hand lamina $1 b$ (which, in the middle of the lateral geniculate body is shorter in transverse extent than lamina 1a) contains normal large cells on the right side, while, on the left all the cells are much reduced in size. Of the medium-sized cell laminae, on the left side laminae $2 b$ and $3 b$ are normal, the cells staining well and their dendrites showing up very distinctly, while laminae $2 a$ and $3 a$ consist of cells which have undergone complete chromatolysis and 
are very much shrunken. On the right side laminae $2 a$ and $3 a$ are normal in every respect, while laminae $2 b$ and $3 b$ have atrophied. A close search through the atrophied layers on both sides occasionally reveals what appears to be a normal cell, but these are extremely rare. Thus, on the left side, in lamina $3 a$ there were found in one section three normal cells, in another section five, and in another two. Similarly in lamina $2 b$ on the right side there could be detected one, two or three cells of normal appearance in odd sections. Such occasional normal cells among many thousands of atrophied cells obviously can be of little significance. The changes which occur in the lateral geniculate body of the human brain after unilateral optic atrophy are exactly similar to those found in the lateral geniculate body of the monkey, and are even more precisely and definitely marked.* Crossed fibres of the optic tract evidently terminate in laminae $1 a, 2 b$ and $3 b$, while uncrossed fibres end in laminae $1 b, 2 a$ and $3 a$. The functional relation of the laminae of these two groups is further indicated by the fact that, as can be followed by a study of serial sections, the individual laminae are in some part of their extent structurally continuous with each other. This is shown in the microphotographs in Plate 2. The sections shown here have not been made:in precisely corresponding planes and they show clearly that in some planes (as shown here on the left side) laminae $3 b, 2 b$ and $1 a$ are in direct continuity with each other at their lateral extremities, while in other planes (as shown here on the right side) laminae $3 a, 2 a$ and $1 b$ are continuous. Similar relations of alternating laminae are also evident enough in the lateral geniculate body of the monkey. Thus in each geniculate body there are two sets of three laminae, the individual laminae of each separate set being structurally continuous with each other, and each set interlocking with the other. The two sets of laminae, moreover, are related one to the termination of crossed fibres of the optic tract and the other to the termination of uncrossed fibres.

\section{REFERENCES}

1. Bellonci, J.-Ueber die centrale Endigung des Nervus opticus bei den Vertebraten. Zeits. f. wiss. Zool., Bd. XLVII, p. 1, 1888.

2. Biemond, A.-Experimentell-anatomische Untersuchungen über die cortifugalen optischen Verbindungen bei Kaninchen und Affen. Zeits. $f . d$. gesamte Neur. u. Psych., Bd. CXXIX, Heft. 1 and 2, p. 65, 1930.

3. Bouman, K. H.-Experimenteele Onderzoekingen over het Cerebrale Optische Stelsel. Academisch Proefschrift. Univ. v. Amsterdam, 1905.

* The visual cortex of the calcarine region of both sides in this case of unilateral optic atrophy was sectioned and examined. No perceptible difference in the development of the two layers of granule cells in the lamina granularis interna could be detected. Thus no evidence is provided in support of the suggestion made by Barany that one layer is related to homolateral visual impulses and the other layer to heterolateral visual impulses. 
4. Brouwer, B.-Experimentell-anatomische Untersuchungen über die Projektion der Retina auf die primären Opticus-zentren. Schweiz. Arch.f. Neur. u. Psych., Bd. IX, p. 118, 1923.

5. Cairney, J.-A general survey of the forebrain of Sphenodon punctatum. Jl. Comp. Neur., Vol. XLII, p. 255, 1926.

6. Cajal, S. R. y.-Histologie du Système Nerveux. Paris, 1911.

7. Clark, W. E. Le Gros.-The Thalamus of Tupaia minor. Jl. Anat., Vol. LXIII, p. 117, 1929.

8. The Thalamus of Tarsius. Jl. Anat., Vol. LXIV, p. 371, 1930.

9. Proceedings of Anatomical Society. Jl. Anat., Vol. LXVI, p. 138, 1931.

10. The Brain of Microcebus murinus. Proceedings of Zoological Society, London, Part II, p. 30, 1931.

11. Durward, A.-The cell masses in the forebrain of Sphenodon punctaturn. Jl. Anat., Vol. LXV, p. 8, 1930.

12. Edinger, L.-Untersuchungen über die vergleichende Anatomie des Gehirns. 1V. Frankurt, 1899.

13. Gaupp, E.-Anatomie des Frosches. Abt. 2, Braunschweig.

14. Gurdjian, E. S.-The diencephalon of the albino rat. Jl. Comp. Neur., Vol. XLIII, No. 1, p. 1, 1927.

15. Herrick, C. J.-The internal structure of the midbrain and thalamus of Necturus. Jl. Comp. Neur., Vol. XXVIII, No. 2, p. 215, 1917.

16. Huber, G. C., and Crossby, E. C.-On thalamic and tectal nuclei and fibre paths in the brain of the American alligator. Jl. Comp. Anat., Vol. XL, No. 1, p. 97, 1926.

17. Somatic and visceral connections of the diencephalon. Arch. of Neur. and Psych.. Vol. XXII, p. 187, 1929.

18. Kappers, C. U. Ariens.-Die vergleichende Anatomie des Nervensystems der Wirbelthiere und des Menschen. Haarlem, 1921.

19. Kornyey, S.-Zur vergleichenden Morphologie des lateralen Kniehöckers der Säugethiere. Arbeit. aus dem Neur. Inst. an der Wien. Univ., Bd. XXX, 1927.

20. de Lange, S. J.-Das $Z$ wischenhirn und das Mittelhirn der Reptilien. Folia Neurobiologica, Bd. VII, p. 67, 1913.

21. Loepp, W. H.-Ueber die zentralen Opticusendigungen beim Kaninchen. Anat. Anz., Bd. XL, 1912.

22. Minkowski, M.-Ueber den Verlauf, die Endigung und die zentrale Reprasentation von gekreuzten und ungekreuzten Sehnervenfasern bei einigen Säugethieren und beim Menschen. Schweiz. Arch. f. Neur. u. Psych., Vol. VII, p. 201, 1919.

23. Rioch, D. M.-Studies on the diencephalon of carnivora. Jl. Comp. Neur., Vol. XLIX, p. 1, 1929.

24. Shanklin, W. M.-The central nervous system of Chamaeleon vulgaris. Acta Zoologica., Bd. XI, p. 425, 1930.

25. Tretjakoff. D.-Das Nervensystem von Ammocoetes. II. Gehirn. Arch. f. mikr. Anat., Bd. LXXIV, 1909.

26. Tsai, C.-The optic tracts and centres of the opossum. Jl. Comp. Neur., Vol. XXXIX, No. 2, p. 173, 1925.

27. Wlassak, R.-Die optischen Leitungsbahnen des Frosches. Arch.f. Anat. u. Phys., 1893.

28. Woollard, H. H. - Notes on the retina and lateral geniculate body of Tupaia, etc. Brain, Vol. XLIX, Part I, 1926. 